\title{
Restrições à ocorrência da CV e do pronome lexical sujeitos no português
}

Eliane Mourão Pontifícia Universidade Católica de Minas Gerais

\section{Abstract}

Analysis of the presence of an empty category and a lexical pronoun in the subject position of tensed clauses in Portuguese. Identification of general structural factors which determine a restriction pattern for the occurence of these categories; and identification of structural factors which are specific to particular types of sentences and which determine change in the pattern. 


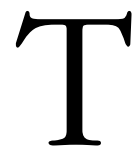

ratando da possibilidade de algumas línguas apresentarem uma categoria vazia (CV) na posição de sujeito de sentenças finitivas conto (sentenças com tempo), CHOMSKY (1982) propõe, no. contexto da Teoria da Regência e Ligação (TRL), o Parâmetro Pro-drop. Tal parâmetro permite estabelecer uma oposição entre as línguas que não admitem sujeito nulo, como o inglês e o francês, e as línguas que admitem a ocorrência do sujeito nulo - Línguas Pro-drop -, entre elas o italiano, o espanhol e o português.

No quadro da descrição funcional das CVs em geral, a CV sujeito de sentenças finitivas, possível nas Línguas Pro-drop, seria pro: uma CV que ocupa o lugar de um pronome lexical e cujo conteúdo é recuperado como o do pronome - através da correferência ou da referência disjunta. Em outras palavras, pro alternaria livremente com um pronome lexical.

Embora em CHOMSKY (1982) pro possa recuperar qualquer um dos traços de pessoa $-1^{\underline{a}}, 2^{\underline{a}}$ ou $3^{3}$ pessoa - , tratamos aqui apenas da $\mathrm{CV}$ que deve recuperar a $3^{\underline{a}}$ pessoa. Visto que estamos preocu-pados exclusivamente com explicações de ordem estrutural, procuramos evitar ao máximo a interferência de fatores pragmáticos em nossos dados, e as categorias de $1^{\underline{a}}$ e $2^{\underline{a}}$ pessoas permitem tal interferência. É justamente com base na necessidade ou não de interferência de fatores pragmáticos na identificação de pronomes que BENVENISTE (s.d.) estabelece uma distinção entre os mesmos:

(...) os pronomes não constituem uma classe unitária, mas espécies diferentes segundo o modo de linguagem do qual eles são signos. Uns pertencem à sintaxe da língua, outros são característica daquilo que chamaremos 'instâncias de discurso', isto é, os atos discretos e únicos através dos quais a língua se atualiza em fala para um locutor. (BENVENISTE, s,d.:43) 
E ainda:

Qual é, pois, a 'realidade' à qual se refere eu ou tu? Unicamente uma 'realidade de discurso', que é algo muito singular. Eu só pode definirse em termos de 'locução', não em termos de objetos, como acontece com um signo nominal. (op. cit.:44)

Restringindo-nos à $3^{3}$ pessoa, observamos que, contrariando a análise proposta na TRL, o português não admite a alternância livre entre a CV denominada pro e o pronome lexical, conforme podemos observar em dados como o de 1 abaixo:

1) Maria disse que [ CV/ela] virá para o jantar.

No contexto estrutural dado por 1, a CV e o pronome lexical ela não têm, na verdade, o mesmo conteúdo. Para a CV é exigida a correferência com o sujeito da oração principal:

2) Maria ${ }_{\mathrm{i}}$ disse que $\left[\mathrm{CV}_{\mathrm{i},{ }^{*} \mathrm{j}}\right]$ virá para o jantar.

Quanto ao pronome ela, tanto a correferência com Maria como a referência disjunta - a referência a um SN que não se encontra na frase, mas no texto a que a frase pertence - são possíveis:

3) Maria $a_{i}$ disse que $\left[e a_{i, j}\right]$ virá para o jantar.

Visto que a CV e o pronome lexical recuperam seu conteúdo de forma diferente em construções como a de 1, podemos dizer que, no português, há restrições para a alternância livre entre essas categorias. Diante desse fato, as seguintes questões fazem-se pertinentes:

4) a. Em que tipos de construções do português podemos identificar restrições à alternância livre entre uma CV e um pronome lexical na posição de sujeito de sentenças finitivas?;

b. Que princípios da Gramática interagem, e como interagem, na determinação de tais restrições? 
No levantamento das construções do português em que uma CV e um pronome lexical não alternam livremente, distinguimos 4 tipos de construções complexas:

\section{5) Construções com sentença adjunta}

a. Fernanda $a_{i}$ cumprimentou Beatriz $j_{j}$ quando $\left[\mathrm{CV}_{\mathrm{i},{ }^{*}, i, 1}\right]$ chegou na festa.

b. Fernanda ${ }_{i}$ cumprimentou Beatriz quando $_{j}\left[\mathrm{ela}_{\mathrm{i}, \mathrm{j}, \mathrm{l}}\right]_{\text {chegou na }}$ festa.

\section{Construções com sentença coordenada}

c. Antônio ${ }_{i}$ encontrou $\mathrm{Marco}_{j}$, mas $\left[\mathrm{CV}_{\left.\mathrm{i},{ }^{,},{ }_{j, 1}\right]}\right]$ não foi para a reunião.

d. Antônio ${ }_{i}$ encontrou Marco $_{j}$, mas [ele $e_{i, j, 1}$ ] não foi para a reunião.

\section{Construções com sentença relativa}

e. Vera ${ }_{i}$ deu para Maria ${ }_{j}$ as meias que $\left[\mathrm{CV}_{\mathrm{i},{ }^{,}, \mathrm{p}, \mathrm{l}}\right]$ rasgou.

f. Vera ${ }_{i}$ deu para Maria ${ }_{j}$ as meias que $\left[\right.$ ela $\left._{\mathrm{i}, \mathrm{j}, 1}\right]$ rasgou.

\section{Construções com sentença completiva}

g. Maria ${ }_{i}$ disse a $\mathrm{Cleo}_{\mathrm{j}}$ que $\left[\mathrm{CV}_{\mathrm{i},{ }^{, j}, \mathrm{i}, \mathrm{l}}\right]$ comprará as frutas.

h. Maria ${ }_{i}$ disse a Cleo que $\left[\right.$ ela $\left._{\mathrm{i}, \mathrm{j}, \mathrm{l}}\right]$ comprará as frutas.

Nessas construções, a ocorrência da CV e do pronome lexical segue um padrão: a CV tem de ser correferente com o sujeito da oração principal e o pronome admite tanto a correferência - seja com um elemento na posição de sujeito, seja com um elemento em outra posição - como a referência disjunta.

No entanto, nem sempre tal padrão é seguido. Nas construções com sentença adjunta, o padrão é rompido quando a CV ou o pronome lexical se encontram na oração principal, como mostram os dados de 6 abaixo:

6) a. $\left[\mathrm{CV}_{\mathrm{u}_{i}, p_{i}, 1}\right]$ estava nervosa quando Fernanda $\mathrm{i}_{\mathrm{i}}$ cumprimentou Beatriz.

b. $\left[\right.$ Ela $_{*_{i}, p_{i}, 1}$ ] estava nervosa quando Fernanda ${ }_{i}$ cumprimentou Beatriz. 
Em 6 não é possível a ocorrência da CV e a ocorrência do pronome lexical está condicionada à referência disjunta.

Nas construções com sentença coordenada, o padrão é rompido quando está presente o conectivo $e$, como se verifica em 7 abaixo:

7) a. Antônio ${ }_{i}$ encontrou $\mathrm{MarCO}_{j}$ e $\left[\mathrm{CV}_{\left.\mathrm{i},{ }^{*},{ }^{*}\right]}\right]$ foi para a reunião.

b. Antônio ${ }_{i}$ encontrou Marco $_{j}$ e $\left[e e_{*_{i}, j}\right]$ foi para a reunião.

Nas construções coordenadas com conectivo e, o pronome lexical, diferentemente do que definimos como fazendo parte do seu padrão de ocorrência, não admite a correferência com um sintagma nominal (SN) na posição de sujeito.

Finalmente, nas construções com sentença completiva, o padrão é rompido quando o verbo da sentença completiva é do tipo subjuntivo:

8) a. Pedro ${ }_{i}$ sugeriu a Marcos ${ }_{j}$ que $\left[\mathrm{CV}_{\left.\mathrm{*}_{\mathrm{i}, j},{ }^{*}\right]}\right]$ saísse da reunião.

b. Pedro ${ }_{i}$ sugeriu a $\operatorname{Marcos}_{\mathrm{j}}$ que $\left[\mathrm{ele}_{\left.\boldsymbol{s}_{\mathrm{i}, j, 1}\right]}\right]$ saísse da reunião.

Em 8, tanto a CV como o pronome lexical admitem apenas a correferência com o SN-não-sujeito.

Se há um padrão de ocorrência para a CV e o pronome lexical, e se, em alguns contextos, esse padrão é rompido, duas perguntas devem ser consideradas:

9) a) Que fatores estruturais gerais determinam restrições à alternância livre entre a CV e o pronome lexical?

b) Que fatores estruturais específicos a determinados tipos de construção alteram o padrão geral de restrições?

\section{O PADRÃO DE OCORRÊNCIA DA CV E DO PRONOME LEXICAL}

Como a CV e o pronome lexical sujeitos constituem manifestações de um SN, devemos considerar o seu licenciamento e a sua identificação sob a perspectiva do licenciamento e da identificação dos SNs em geral. Nesse sentido, assumimos primeiramente que um $\mathrm{SN}$ se define pelo seguinte complexo de traços: 
10) - de gênero

- de pessoa

- de número

- de caso

Em outras palavras, o SN está sujeito ao seguinte princípio, que atua na Forma Lógica (FL):

\section{1) Princípio de Identificação de um SN}

Todo SN deve ser identificado pelos traços de gênero, de pessoa, de número e de Caso.

Além dos traços elencados em 11, um SN deve obter Índice Referencial (Índice-R), o índice necessário para que denote um objeto no Domínio-D. ${ }^{1}$ Assumimos, então, conforme BOUCHARD (1984), que na FL há também um princípio que exige que os SNs possuam Índice-R.

\section{2) Princípio de Denotabilidade}

Um SN denotará um objeto no Domínio-D se esse SN tiver um Índice-R. (BOUCHARD, 1984:17. Traduzido do inglês.)

Qualquer SN deve ocorrer sob condições estruturais tais que obtenha os traços de 10 e Índice-R, a fim de ser identificado como um SN, ou seja, qualquer manifestação de SN deve encontrar as condições estruturais necessárias para que se construa como um SN e seja identificada como tal. Consideramos, assim, que um SN se constrói na Gramática e as diversas manifestações de SN diferem entre si segundo o modo como se constroem como um SN.

A CV na posição de sujeito de uma sentença finitiva se caracteriza pelo fato de, na Estrutura Profunda (EP), não receber Índice-R e não possuir nenhum dos traços necessários a um SN. A CV deve obter esse conteúdo através da Concordância com CONC e da Ligação com um SN-antecedente. Na Concordância com CONC, a CV obtém os traços de pessoa, número e Caso. Mas, se a CV recebe Caso, o Caso não é visível, visto que ela não possui conteúdo fonético. Além disso, 
na Concordância com CONC, a CV não obtém nem o traço de gênero nem Índice-R, dado que CONC também não os possui. CONC não é, portanto, suficiente para identificar a CV. É necessário que ela se ligue a um $\mathrm{SN}$-antecedente a fim de obter visibilidade de Caso, o traço de gênero e Índice-R. Conforme CHOMSKY (1982), afirmamos que a Ligação entre a CV e seu antecedente está sujeita ao Princípio B da Teoria da Ligação:

\section{3) Princípio B}

Um pronome é livre na sua categoria de regência.

Formando uma espécie de cadeia com CONC e com um SNantecedente, a CV obtém todo o conteúdo necessário a um SN. Em 14 abaixo, apresentamos o esquema da forma como a CV se constrói como um SN:

\section{4) CV-sujeito}

- gênero

Ligação com um SN

- $\operatorname{pessoa}([-$ pessoa] $)$ Concordância com CONC

- número Concordância com CONC

- Caso ([- Caso $])^{2}$ Concordância com CONC

- Visibilidade de Caso Ligação com um SN

- Índice-R Ligação com um SN

O pronome, por sua vez, traz do Léxico, como parte do seu conteúdo lexical, os traços de gênero e pessoa ([- pessoa]); na Concordância com CONC, obtém o traço de número e o traço de Caso ([- Caso]). Mas, diferentemente do Nome, o pronome lexical não obtém Índice-R ao ser introduzido na EP. O pronome adquire esse conteúdo por meio da Ligação (conforme o Princípio B da Teoria da Ligação) com um SN-antecedente. Resumindo, o pronome lexical na posição de sujeito das sentenças finitivas do português se constrói como um $\mathrm{SN}$ de acordo com o esquema a seguir: 


\section{5) pronome lexical sujeito}

- gênero ………………......... no Léxico

- pessoa ([- pessoa]) .............. no Léxico

- número .................................. Concordância com CONC

- Caso ([- Caso]) ……………. Concordância com CONC

- Índice-R ................................. Ligação com um SN

Embora a CV e o pronome lexical se assemelhem no que diz respeito ao conteúdo que devem adquirir e aos mecanismos a que estão sujeitos na obtenção desse conteúdo - Concordância e Ligação -, eles se diferenciam no que diz respeito à seleção de um $\mathrm{SN}$-antecedente. Em outras palavras, a CV e o pronome lexical são licenciados de forma semelhante, mas se distinguem quanto à forma como são identificados. Desse modo se explica o que denominamos padrão de ocorrência da CV e do pronome lexical: na Ligação com um $\mathrm{SN}$-antecedente a CV deve obter visibilidade de Caso, mas o pronome lexical não.

Dado que a CV deve obter visibilidade de Caso através da Ligação com um SN-antecedente, tem de haver uma equivalência entre o Caso que a CV obtém na Concordância com CONC e o Caso do $\mathrm{SN}$-antecedente. Além disso, o $\mathrm{SN}$-antecedente deve pertencer à construção onde a CV ocorre (deve ter Caso na mesma construção). Visto que para ter Caso visível a CV deve ter conteúdo fonético, o elemento que não tem corpo fônico na construção não a identifica. Assim, em 16 abaixo, a CV admite Maria como antecedente, mas não admite Cleo ou um SN que não pertence à construção (um SN que não tem Caso na construção):

16) Maria ${ }_{i}$ disse a $\mathrm{Cleo}_{j}$ que $\left[\mathrm{CV}_{\mathrm{i},{ }^{*}, i, 1}\right]$ comprará as frutas.

A espécie de cadeia formada pela CV, CONC e seu antecedente, no caso Maria, possui um único Índice-R e apenas um gênero, uma pessoa, um número e um Caso. A Ligação da CV com Cleo criaria uma cadeia impossível, com dois Casos diversos; e a Ligação com um SN 
não pertencente à construção não possibilitaria a obtenção de conteúdo fônico e, conseqüentemente, não possibilitaria a obtenção de visibilidade de Caso.

Mas o pronome lexical, por possuir conteúdo fonético e, portanto, não precisar obter visibilidade de Caso através da Ligação com um SN-antecedente, admite, em uma construção como a de 16 acima, tanto a Ligação com Maria ou com Cleo como com um SN que não pertence à construção:

17) Maria $_{\mathrm{i}}$ disse a $\mathrm{Cleo}_{\mathrm{j}}$ que $\left[\mathrm{ela}_{\mathrm{i}, \mathrm{j}, 1}\right]$ comprará as frutas.

Procurando formalizar as exigências relativas à recuperação do conteúdo da CV, podemos dizer que a CV está sujeita à Regra de Controle Generalizada:

\section{8) Regra de Controle Generalizada}

Coindexar um pronominal vazio com o elemento nominal mais próximo. (HUANG, 1984:552. Traduzido do inglês.)

Para mostrar como tal regra se aplica, voltemos aos dados já apresentados em 16 e 17 :

19) a. Maria ${ }_{i}$ disse a $\mathrm{Cleo}_{j}$ que $\left[\mathrm{CV}_{\mathrm{i},{ }^{*},{ }^{*}, \mathrm{l}}\right]$ comprará as frutas.

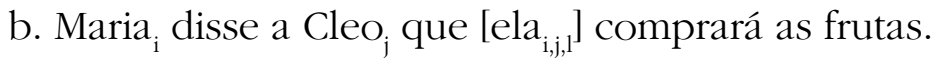

Consideremos a ocorrência da CV e do pronome lexical nas estruturas correspondentes às construções de 19: 
20) a.
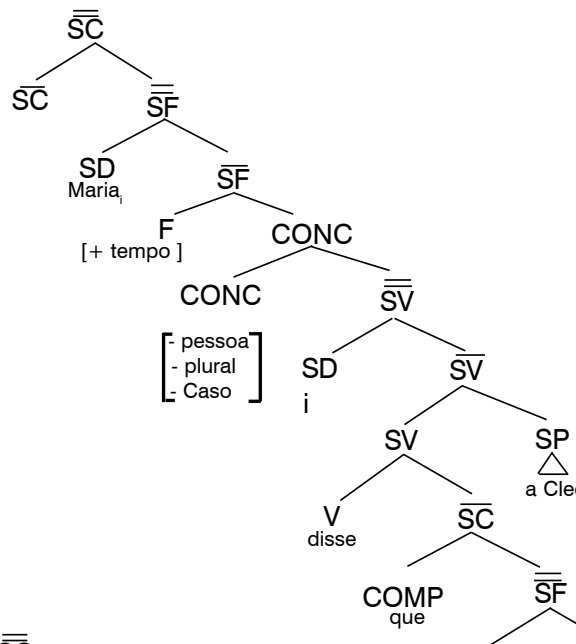

20) b.

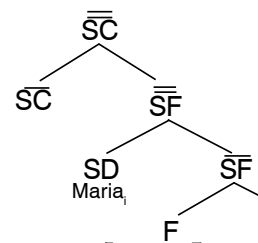

[+ tempo]

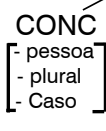

CONC

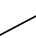

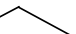

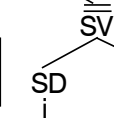

SV
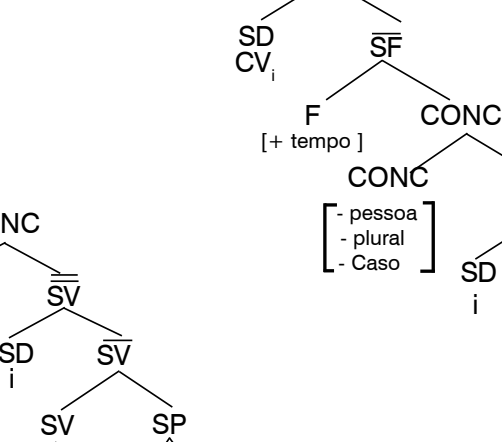

[+ tempo ]

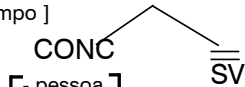

$\left[\begin{array}{l}\text { - pessoa } \\ \text { - plural } \\ \text { - Caso }\end{array}\right]$

SD
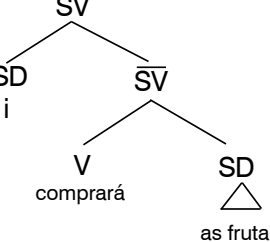

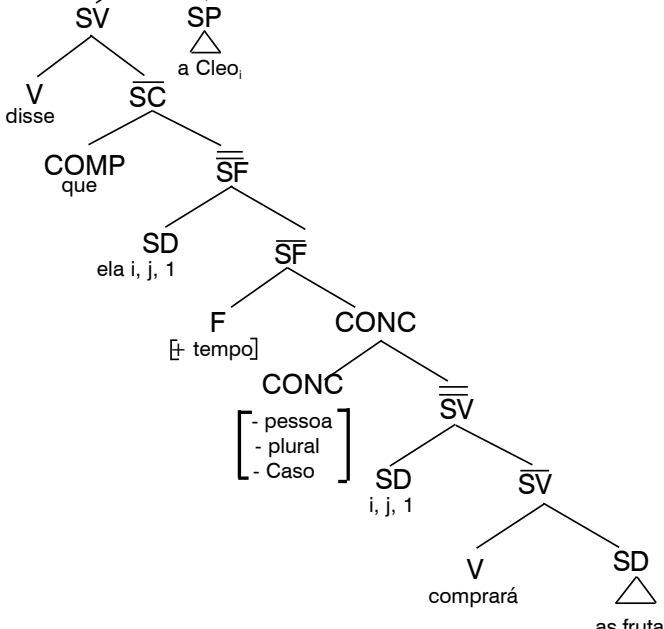


Como o pronome lexical - em 20b - não está sujeito à Regra de Controle Generalizada, ele pode tomar como antecedente Maria, Cleo ou um SN que não pertence à construção, independentemente da "distância" em que se encontra desses SNs. Mas o mesmo não se dá com a CV - em 20a -, que está sujeita à Regra de Controle Generalizada. A CV deve tomar como antecedente o SN mais próximo, que em 20a é Maria, o único SN que a C-comanda. Nesse caso, vale a seguinte definição de termo maispróximo:

21) A é mais próximo de $B$ do que de $C$ se $A$

C-comanda

B. (HUANG, 1984:552-3)

Assim, se a CV, segundo o seu padrão de ocorrência, não admite nem a correferência com um SN não-sujeito nem a referência disjunta, esse fato se deve à atuação da Regra de Controle Generalizada como formulada por HUANG (1984).

\section{O ROMPIMENTO DO PADRÃO DE OCORRÊNCIA DA CV E DO PRONOME LEXICAL}

\subsection{Estruturas de adjunção}

ASSUNÇÃO (1993), ao analisar a ocorrência de uma CV-objeto em construções do português, distingue dois tipos de estrutura oracional complexa: de adjunção e de complementação. Além disso, o autor caracteriza o processo de adjunção como um processo que se estabelece por meio de um nó sintático não-selecionado, sujeito a diferentes realizações fonéticas. Assim, consideramos como estruturas de adjunção aquelas construções que denominamos construções com sentença adjunta, construções com sentença relativa e construções com sentença coordenada. Embora essas construções sejam distintas entre si no que diz respeito à manifestação fonética do nó adjuntor, elas se opõem às estruturas de complementação pelo fato de não serem selecionadas. 
Consideramos ainda, como propõe KAYNE (1993), que as estruturas de adjunção têm uma configuração assimétrica; ${ }^{3}$ nelas, o nó adjuntor funciona como um operador, como um elemento associado à posição de complementador (COMP) e com o papel de quantificador.

Assumindo tais pressupostos, analisaremos aqui a ocorrência da $\mathrm{CV}$ e do pronome lexical nas construções com sentença adjunta e com sentença coordenada, procurando conhecer os fatores estruturais específicos dessas construções que determinam alterações no que seria o padrão de ocorrência da CV e do pronome lexical.

Quanto às construções com sentença adjunta, tomamos quando como um elemento adjuntor que, conforme defende KAYNE (1993) para as estruturas de adjunção em geral, estabelece uma assimetria sintática entre a sentença adjunta e a sentença que recebe a adjunção. Dada a necessidade de assimetria sintática, podemos entender por que, em $C V$ estava nervosa quando Fernanda cumprimentou Beatriz e Ela estava nervosa quando Fernanda cumprimentou Beatriz, há rompimento do padrão geral de ocorrência da CV e do pronome lexical: nessas construções a CV e o pronome lexical Ccomandam os virtuais antecedentes Fernanda e Beatriz, como observamos em 22 e 23 , respectivamente: 

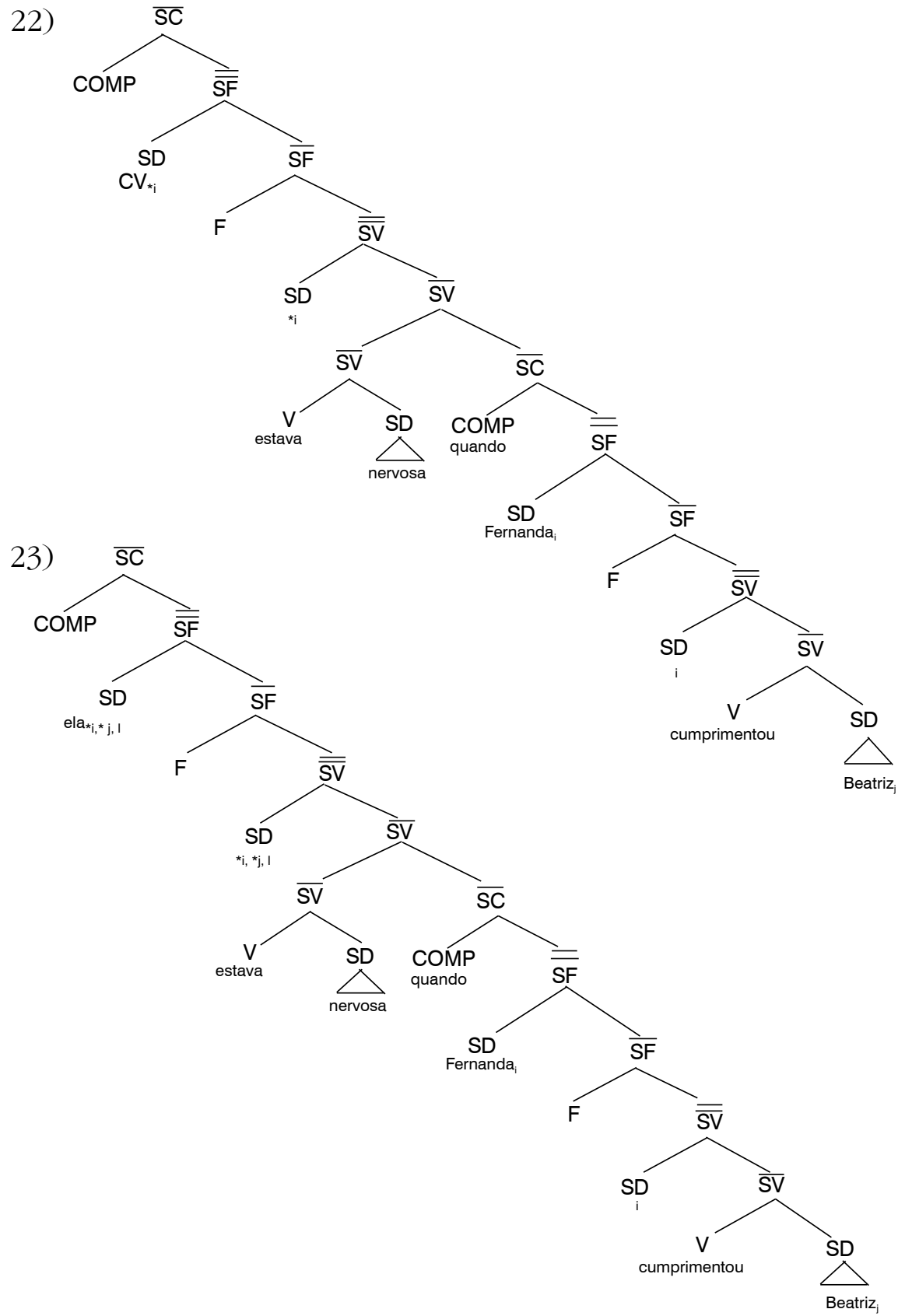
Em 22 e 23, a correferência é impossibilitada devido à atuação do Princípio $\mathrm{C}$ da teoria da Ligação, o qual exige que uma Expressão-R seja livre. Se, conforme o padrão, a CV não pode ser correferente com o sujeito Fernanda, a sua ocorrência é impossível; e, se o pronome lexical não pode ser correferente nem com Fernanda nem com Beatriz, só é possível para ele a referência disjunta.

Quanto às construções com sentença coordenada em que a ocorrência da CV e do pronome lexical não segue o padrão, observemos os seguintes dados do português:

\section{4) Construções com conectivo e}

a. João e Pedro saíram.

b. João comprou e encadernou os livros

c. João comprou os cadernos e os livros.

d. João saiu cedo e voltou tarde.

e. João saiu de carro e ele saiu a pé.

f. João saiu de carro e Pedro saiu a pé.

\section{Construções com conectivo mas}

g. *João mas Paulo saíram.

h. *João comprou mas encadernou os livros.

i. *João comprou os cadernos mas os livros.

j. João saiu cedo, mas voltou tarde.

1. João saiu de carro, mas ele saiu a pé.

m. João saiu de carro, mas Pedro saiu a pé.

Percebemos em 24 que os ambientes de ocorrência do conectivo $e$ e do conectivo mas não são sempre os mesmos, havendo restrição para a ocorrência de mas onde e é permitido. Sendo assim, podemos atribuir a diferença entre ee mas ao tipo de constituinte que cada um pode ligar. Sem perder de vista a proposta de KAYNE (1993), segundo a qual o conectivo é um elemento adjuntor, um elemento que estabelece uma relação assimétrica entre o constituinte adjunto e um outro constituinte, afirmamos que mas liga sentenças e $e$ liga qualquer constituinte. 
Se $e$ liga qualquer constituinte, podemos dizer que uma construção como Antônio encontrou Marco e CVfoi para a reunião corresponde a uma coordenação de Sintagmas Verbais (SVs), não comportando uma CV. Nesse sentido, devemos falar que a construção é Antônio encontrou Marco e foi para a reunião, em que encontrou Marco e foi para a reunião são SVs que compartilham um mesmo sujeito - o SN Antônio, o qual encabeça o Sintagma Flexional (SF), ou seja, aloja-se na posição de Especificador do SF, conforme a estrutura apresentada em 25 abaixo:

25)

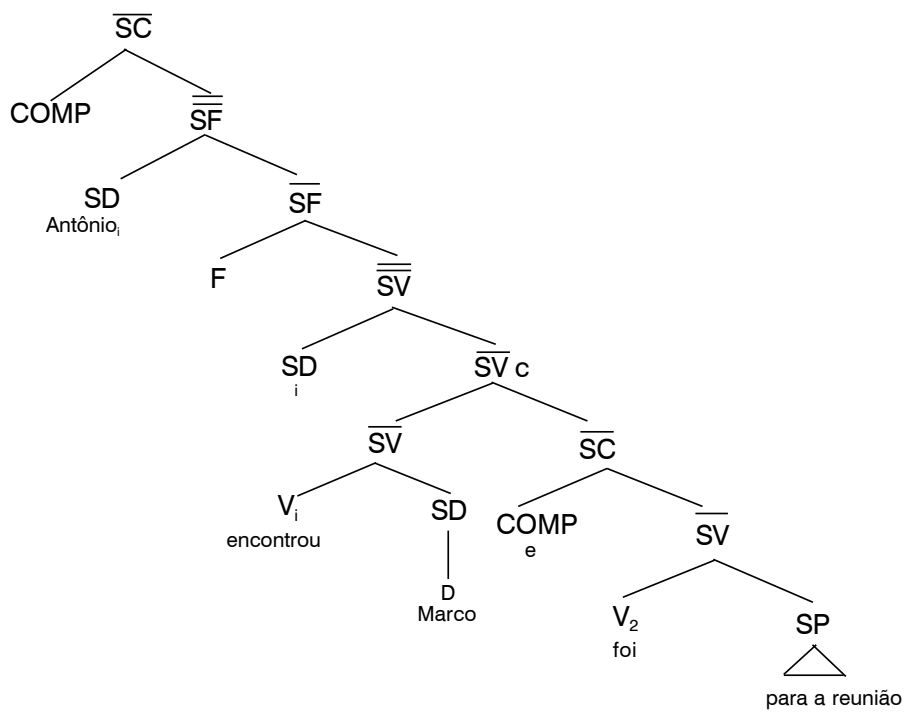

Realmente, no tipo de estrutura de 25 há apenas um Tempo em FLEX para os dois SVs coordenados:

26) a. Antônio encontra [- passado] Marco e vai [- passado] para a reunião.

b. Antônio encontrou [+ passado] Marco e foi [+ passado] para a reunião. 
c. *Antônio encontra [- passado] Marco e foi [+ passado] para a reunião.

d. ?Antônio encontrou [+ passado] Marco e vai [- passado] para a reunião.

Considerando que os traços [- passado] e [+ passado] marcam, respectivamente, a ausência e a presença de Tempo, observamos que em 26 só são possíveis, sem dúvida, a ausência de Tempo ([- passado]... [- passado]) e a presença de Tempo ([+ passado]... [+ passado]). Em outras palavras, o conectivo e exige a correlação de Tempo entre os constituintes que coordena. Mesmo que aceitemos a possibilidade de variação de Tempo, esta deve estar condicionada à presença do traço [+ passado] no primeiro SV. É o que acontece no caso duvidoso de $26 \mathrm{~d}$, que seria inquestionavelmente admissível com a presença do termo agora: Antônio encontrou Marco e agora vai para a reunião. Agora funciona como um operador de Tempo que garante a correlação temporal do segundo SV com o primeiro.

Enquanto em construções como Antônio encontrou Marco e foi para a reunião há uma coordenação de SVs, em Antônio encontrou Marco e ele foi para a reunião há uma coordenação de SFs. Se $e$ coordena qualquer constituinte, à presença de um pronome lexical corresponde uma coordenação de SFs: 
27)

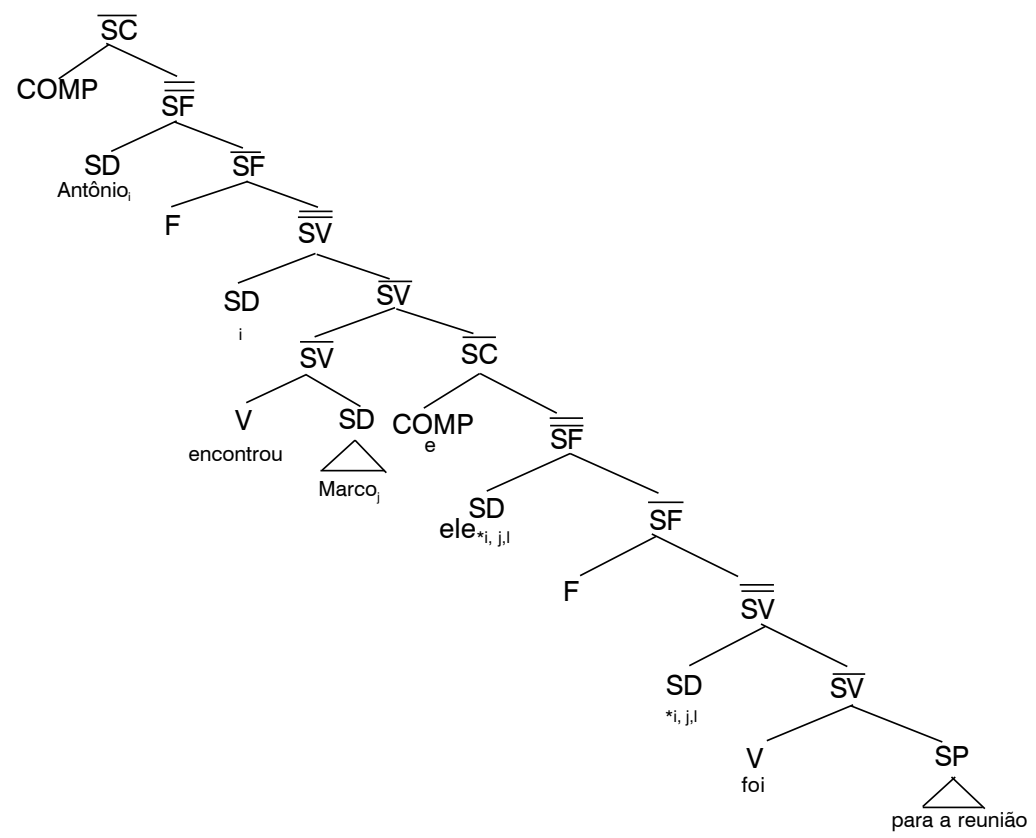

Embora, a princípio, a estrutura de 27 não exclua a correferência do pronome lexical com o SN-sujeito, deve-se considerar que o que seria a correferência realiza-se por meio de estruturas como a de 25. O que seria a correferência com um SN-sujeito nas estruturas coordenadas com $e$ realiza-se por meio de uma coordenação de SVs que compartilham um mesmo SN-sujeito e não por meio de uma CV ou de um pronome lexical. A língua utiliza-se da possibilidade que constitui a primeira estrutura e não de estruturas como a de 27. Assim, em 27 o pronome lexical admite apenas a correferência com o SNnão-sujeito e a referência disjunta, o que explica o que consideramos um rompimento no seu padrão de ocorrência.

\subsection{Estruturas de complementação}

Distinguimos, anteriormente, as construções em que uma CV e um pronome lexical não alternam livremente em dois tipos: construções cuja estrutura é de adjunção, dentre as quais se incluem as construções 
com sentença adjunta e com sentença coordenada; e construções cuja estrutura é de complementação, dentre as quais se incluem as construções com sentença completiva. As primeiras construções são resultantes do processo de adjunção, um processo sintático que ocorre por meio de um nó adjuntor sujeito a diferentes realizações fonéticas, o qual garante a assimetria sintática das estruturas de adjunção. As construções com sentença completiva, por sua vez, são resultantes do processo de subcategorização da língua: um núcleo verbal seleciona no Léxico um complemento oracional. Essa seleção é projetada na Sintaxe na forma da relação entre um núcleo e seu complemento, uma relação que é assimétrica, assim como a relação entre as sentenças da estrutura de adjunção.

Embora a configuração das estruturas de complementação seja semelhante à das estruturas de adjunção, não é possível afirmar que nas primeiras a CV e o pronome lexical estejam sujeitos às mesmas condições de ocorrência a que estão sujeitos nas últimas. Nas estruturas de complementação os problemas são de natureza diferente. Assumimos, como KEMPCHINSKY (1985) propõe para o espanhol, que a explicação das restrições à ocorrência da CV e do pronome nas estruturas de complementação se encontra no processo de subcategorização da língua, nos mecanismos envolvidos na seleção das sentenças completivas.

No português, há quatro tipos possíveis de complementos oracionais: subjuntivo, indicativo, infinitivo e QU. Nesse ponto, contrariando a análise de KEMPCHINSKY (1985), distinguimos os complementos oracionais do tipo indicativo e do tipo subjuntivo segundo a existência ou não de Tempo em FLEX: os complementos indicativos possuem Tempo em FLEX e os complementos subjuntivos não possuem. Em outras palavras, selecionar um complemento subjuntivo é selecionar uma categoria sem Tempo em FLEX ou [- passado]. Por isso, o FLEX subjuntivo deve estar coindexado com o FLEX da sentença principal, o qual o C-comanda. Assim, a Categoria de Regência do elemento que se encontra no complemento subjuntivo não é o próprio complemento, mas a sentença que o domina imediatamente. 
Contrariando novamente a análise de KEMPCHINSKY (1985), afirmamos ainda que a categoria que a $\mathrm{CV}$ e o pronome lexical podem tomar como antecedente nas construções com complemento subjuntivo é uma categoria não-selecionada.

Assumindo tais pressupostos, consideremos a forma como a CV e o pronome lexical se constroem como um SN nas construções em questão:

28) a. Pedro $\mathrm{i}_{\mathrm{i}}$ sugeriu a Marcosj que $\left[\mathrm{CV}_{\left.\mathrm{w}_{\mathrm{i}, \mathrm{j}^{*}}\right]}\right]$ saísse da reunião.

b. Pedro ${ }_{i}$ sugeriu a Marcosj que $\left[e^{2} e_{*_{i}, j, 1}\right]$ saísse da reunião.

Se, em 28, a Categoria de Regência da CV e do pronome lexical não é a sentença completiva, mas sim a construção como um todo, temos de admitir, então, que a CV e o pronome se ligam no interior de sua Categoria de Regência. Esse fato não constitui um problema se consideramos que a ligação se dá com uma posição não-argumental. Conforme afirmamos anteriormente, a categoria a Marcos em 28 não é selecionada, é, sim, uma categoria adjunta. Como a CV e o pronome, nesse caso, se ligam no interior da sua Categoria de Regência a uma posição não-argumental, temos, na verdade, variáveis, e não pronominais.

A análise faz sentido se consideramos o licenciamento e a identificação tanto do Sintagma Preposicional (SP) a Marcos como da CV e do "pronome". Tratemos, primeiramente, de a Marcos com relação à CV. Para ser licenciado, a Marcos, que se encontra numa posição não-argumental, deve obter função $\theta$, o que é possível se a $\mathrm{CV}$, que se encontra em uma posição argumental, o toma como antecedente. A CV, por sua vez, não possui na EP nenhum dos traços necessários a um $\mathrm{SN}$, a saber, os traços de gênero, pessoa, número e Caso, além de não possuir Índice-R. Através da ligação com um antecedente, a CV deve obter esse conteúdo. Em 28, o antecedente da CV, a categoria através da qual ela obtém seus traços necessários, a fim de ser licenciada e identificada como um SN, é o SP a Marcos.

A ligação da CV com a Marcosé uma ligação necessária, sem a qual a gramaticalidade de 28 é comprometida. Se, nessa construção 
a Marcos é antecedente de um outro SN que não a CV, forma-se um complexo com mais de um Índice-R, ou seja, um complexo impossível. Por outro lado, a CV, que possui função $\theta$, só pode se ligar, na sua Categoria de Regência, a uma posição não-argumental.

Mas ainda temos um problema a considerar com relação à ligação entre a CV e uma categoria adjunta em construções como a de 28: a CV, que ocupa a posição de sujeito e, portanto, deve ser marcada para Caso nominativo, se liga a uma categoria que possui Caso oblíquo. Esse fato deve ser tratado sob a perspectiva da "prevalência" de traços. Na ligação entre um SN e seu antecedente, se o antecedente é um complexo constituído por elementos com traços de gênero diferentes, prevalece para o complexo como um todo o traço masculino:

29) [Helena e Pedro ${ }_{i}$ disseram que $\mathrm{CV}_{i} /$ eles $_{i}$ vêm à festa.

Se o complexo é constituído por traços de pessoa diferentes, prevalece uma das pessoas:

30) [Eu e Helena ${ }_{\mathrm{i}}$ dissemos que $\mathrm{CV}_{\mathrm{i}} /$ nós $_{\mathrm{i}}$ vamos à festa.

Mesmo que o complexo seja formado por elementos com traço de número singular, o traço do complexo como um todo é plural:

31) [Helena e Lessy $y_{i}$ disseram que $\mathrm{CV}_{i} /$ elas $_{i}$ vêm à festa.

O que afirmamos com relação aos traços de gênero, pessoa e número vale também para o traço de Caso:

32) Depois que Pedro ${ }_{i}$ encontrou Lessy ${ }_{j}, \mathrm{CV}_{\mathrm{i}-\mathrm{j}}$ foram para a festa.

Em 32, Pedro tem Caso nominativo e Lessy tem Caso acusativo, mas o complexo Pedro-Lessy tem um único Caso, o nominativo, que prevalece sobre o acusativo. Igualmente, em $28 \mathrm{a}-$ Pedro sugeriu la Marcos $_{i}$ I que $C V_{i}$ saísse da reunião-, a CV concorda com CONC, que tem Caso nominativo, e toma como antecedente $a$ Marcos, que tem Caso oblíquo, mas a CV tem apenas um Caso, o nominativo, o qual 
prevalece sobre o oblíquo. Em outras palavras, o complexo CV-a Marcos tem Caso nominativo.

Consideremos, agora, o licenciamento e a identificação de $a$

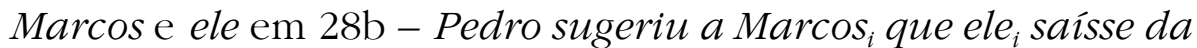
reunião. Como já observamos com relação a 28a, a Marcos, para ser licenciado deve ser tomado como antecedente de um SN com função $\theta$, dado que a Marcosé uma categoria adjunta, encontra-se em uma posição não-argumental. $\mathrm{O}$ antecedente de $a$ Marcos deve ser, necessariamente, ele, visto que ele não tem Índice-R. Por outro lado, ele não possui, na EP, além de Índice-R, os traços de número e Caso. Tomando a Marcos como antecedente, ele obtém tal conteúdo. A sua ligação com a Marcos é, portanto, necessária para que 28b seja gramatical.

\section{CONCLUSÃO}

As alterações no padrão geral de ocorrência da CV e do pronome lexical em algumas construções do português se devem a fatores estruturais que se superpõem às condições de identificação e licenciamento desses elementos: nas construções coordenadas com $e$, a possibilidade de se coordenarem SVs; nas construções com sentença adjunta, a atuação do Princípio C da Teoria da Ligação, que diz respeito não à CV e ao pronome lexical, mas a uma Expressão-R; e nas construções com sentença completiva do tipo subjuntivo, o fato de se ter, na verdade, não uma CV e um pronome lexical, mas variáveis.

Assim, é possível afirmarmos que as alterações no padrão geral de ocorrência da CV e do pronome nas estruturas de adjunção e de complementação não implica a inviabilização da nossa proposta de explicação desse padrão. Independentemente da existência dessas alterações, as condições de identificação e licenciamento da CV e do pronome lexical permanecem válidas.

Para concluir, retomemos as questões que nos propomos em 04:

33) a. Em que tipos de construções do português podemos identificar restrições à alternância entre uma CV e um pronome lexical na posição de sujeito de sentenças finitivas? 
b. Que princípios da Gramática interagem, e como interagem, na determinação de tais restrições?

Respondendo a 33, devemos dizer que no português a CV e o pronome lexical não alternam livremente nas estruturas de adjunção e de complementação porque se constroem de modo diferente como um SN. Tanto a CV como o pronome lexical devem obter Índice-R e os traços de pessoa, de gênero, de número e de Caso para serem licenciados e identificados como um SN, mas os obtêm de modo diferente. Em outras palavras, tanto a CV como o pronome lexical estão sujeitos aos seguintes princípios:

\section{4) Princípio de Identificação de um SN}

Todo SN deve ser identificado pelos traços de gênero, de pessoa, de número e de caso.

Princípio de Denotabilidade

Um SN denotará um objeto no Dominio-D se esse SN tiver um Indice-R. (BOUCHARD, 1984:17. Traduzido do inglês.)

\section{Princípio B}

Um pronome é livre na sua categoria de regência.

Mas somente a CV está sujeita à Regra de Controle Generalizada:

35) Regra de Controle Generalizada

Coindexar um pronominal vazio com o elemento nominal mais próximo. (HUANG, 1984:552. Traduzido do inglês.) 


\section{NOTAS}

${ }^{1}$ Domínio-D é o mesmo que Domínio de denotabilidade, domínio em que, segundo BOUCHARD (1984), se situam os objetos mentais a que as línguas podem se referir, ou seja, o domínio que estabelece uma relação entre os fatos do mundo real e os fatos lingüísticos.

${ }^{2} \mathrm{O}$ Nome na posição de sujeito deve receber o Caso nominativo, que, em oposição ao traço de Caso dos SNs complementos, corresponde ao traço [- Caso]. Se admitimos que a Concordância com CONC licencia um SN-sujeito, devemos admitir também que deve haver um CONC 0, com o qual os SNs complementos concordam a fim de obter Caso.

${ }^{3}$ KAYNE (1993) propõe o Axioma de Correspondência Linear, segundo o qual a ordenação dos elementos terminais de uma árvore deve ser uma função da ordenação dos pares de elementos não terminais em uma relação de C-comando assimétrico.

\section{REFERÊNCIAS BIBLIOGRÁFICAS}

ASSUNÇÃO, Antonio Luiz. As estruturas de objeto nulo sob a perspectiva da Teoria de Princípios e Parâmetros. Belo Horizonte: UFMG, 1993. Dissertação (Mestrado em Lingüística). Faculdade de Letras, Universidade Federal de Minas Gerais, 1993.

BENVENISTE, Émile. O bomem na linguagem. Lisboa: Vega, s.d.

BOUCHARD, Denis. On the content of empty categories. Dordrecht: Foris, 1984.

CALABRESE, Andrea. Some properties of the Italian pronominal system. Mit working papers in linguistics. Massachusetts, v.8, 1-46, 1986.

CHOMSKY, N. Lectures on gouvernment and binding; the Pisa lectures. Dordrecht: Foris, 1981.

Some Concepts and consequence of the theory of gouvernment and binding. Londres: The MIT Press, 1982.

. Linguistic inquiry monograph. 13. Barriers: MIT Press, 1986 a.

. The Managua lectures. London: The MIT Press, 1988.

DOUGHERTY, Ray C. A grammar of coordinate conjoined structures: I. Language. New York, n.46, v.4, 851-898, 1970.

. A grammar of coordinate conjoined structures: II. Language. New York, n.47, v.2, 298-339, 1971.

HUANG, C. T. James. On the distribution and reference of empty pronouns. Linguistic Inquiry. Cambridge, v.15, n.4, 531-574, 1984. 
KAYNE, Richard S. The antisymmetry of syntax. Graduate Center, CUNY, April/ May, 1993.

KEMPCHINSKY, Paula. Operators and binding in subjunctive clausers. West Coast conference on formal linguistics. Stanford, California, v.4, 139-151, 1985.

LOBATO, Lúcia Maria Pinheiro. Sintaxe gerativa do português; da Teoria Padrão à Teoria da Regência e Ligação. Rio de Janeiro: Vigília, 1986.

MONTALBETTI, Mario M. After binding; on the interpretation of pronouns. Tese (Doutorado em Filosofia). Massachusets Institute of Technology, julho, 1984.

RIBEIRO, Ilza. A Teoria da Regência e Ligação; um modelo de gramática. Universidade Estadual de Feira de Santana - BA, 1988. Inédito.

ROTHSTEIN, S. D. The syntactic forms of predication. Tese de Doutorado. MIT. 